\title{
Evaluation of Corrosion Resistance of Mild Steel and Aluminium Using Anodic Inhibitor Method and Passivity
}

\author{
Ali Ramadan Elkais*and Dr Mohamed K Zambri \\ 1,2 Department of Chemical and Petroleum Engineering, Faculty of Engineering, El-Mergib \\ University, Libya \\ DOI: https://doi.org/10.21467/proceedings.2.37 \\ * Corresponding author email: elkaisali@gmail.com
}

\begin{abstract}
Mild steel and Aluminium considered from the metals that commonly used in engineering applications with a high proportion of up to $85 \%$. On the other hand, due to the weakness of its resistance to corrosion environments different methods of corrosion protection are required to increase the resistance level particularly in the marine and acidic environments, where this give the significance of this study to be presented. This research involves studying the effect of some different corrosion resistance of mild steel and Aluminium by applying anodic inhibitor of mild steel (Sodium Dichromate and Potassium dichromate) in sea water environment and Aluminium by using passive film of $\mathrm{Al}_{2} \mathrm{O}_{3}$ in acidic environment (Hydrochloric acid HCL and Nitric acid $\mathrm{HNO}_{3}$ ). An experimental work has been done and evaluation of corrosion resistance have been measured from weight loss during different period of time.
\end{abstract}

Keywords: Corrosion, Corrosion environment, Mild steel, Aluminum, passivity, inhibitor, Anodic

\section{Introduction}

There are many protection methods and measures have been used and considered to prevent or control corrosion process of metals and using the inhibitors was one of these methods. The inhibitor substance has been defined as the substance which can be added to a corrosive environment to decrease the rate of corrosion can occur due to this environment [1 - 3]. Inhibitor sources can be extracts (organic), chemical solutions (Inorganic), Fig (1) illustrates the classification of inhibitors. In addition, the mechanism of how these substances minimize the corrosion rate can be summarized as these substances form a very thin film on the metal surface in different ways that can affect directly on the environment's corrosivity rate [4].

Anodic inhibitors which also can be called "passivation inhibitors" that work on minimizing the anode reaction and gradually cause blocking the anode reaction and supporting occurring the natural reaction of passivation metal surface to produce a very thin layer (film) adsorbed on the metal surface and protecting it from corrosion [6].

(C) 2018 Copyright held by the author(s). Published by AIJR Publisher in Proceedings of First Conference for Engineering Sciences and Technology (CEST-2018), September 25-27, 2018, vol. 1.

This is an open access article under Creative Commons Attribution-NonCommercial 4.0 International (CC BY-NC 4.0) license, which permits any non-commercial use, distribution, adaptation, and reproduction in any medium, as long as the original work is properly cited. ISBN: $978-81-936820-5-0$ 


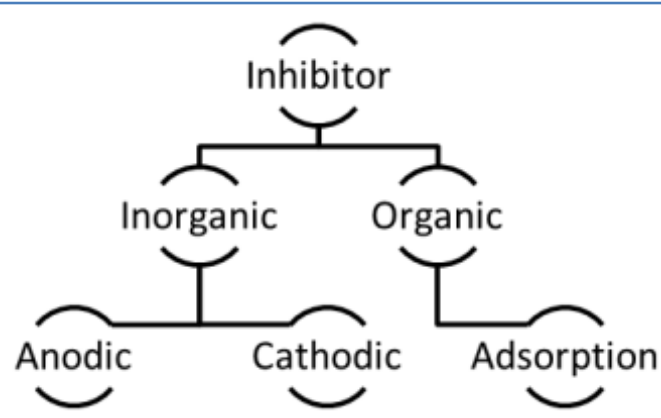

Figure (1): The classification of inhibitors [4]

\section{Materials selection and Methods}

In this work two metals were tested and different protection methods were applied on each of them. The first metal was Mild steel and chemical inhibitor was used to protect the metal from corrosion and sodium dichromate solution was used as coating material which historical been considered as very active inhibitor [5]. When the metal exposed to this chemical solution for a certain of time ( in this work 48 hours) a very thin layer from iron oxide and chromium oxide was produced (Eq. 1) where this layer works to protect the mild steel surface from corrosion by isolating it from surrounding environment (sea water \& atmosphere).

$2 \mathrm{Fe}_{(\mathrm{s})}+\mathrm{Na}_{2} \mathrm{Cr}_{2} \mathrm{O}_{7(\mathrm{aq})}+2 \mathrm{H}_{2} \mathrm{O} \longrightarrow \mathrm{Fe}_{2} \mathrm{O}_{3}+\mathrm{Cr}_{2} \mathrm{O}_{3}+\mathrm{NaOH}_{(\mathrm{aq})}$

The second metal was Aluminium and has been protected experimentally also by an oxide layer produced on the metal surface in different way (passivation inbibitor). This experiment is to prove that not all environments can produce the protection layer even they are have the same classifications (e.g. acids). In this work an Aluminium bar was exposed to different environments ( $\mathrm{HCL} \& \mathrm{HNO}_{3}$ ) and an Aluminium oxide layer was produced from the reaction between the Nitric acid and aluminium surface to protect the metal from the corrosive environment.

\section{Experimental work and results}

\subsection{Mild steel protection}

In this experiment a sample of mild steel has been used to test the ability of a specific chemical inhibitor (Sodium dichromate Solution) to protect the metal surface from corrosion in two different environments (sea water \& atmosphere). Sodium dichromate solution was prepared in two concentrations which are $0.1 \mathrm{M}$ and $0.5 \mathrm{M}$ and the following point were applied and considered:

- The sample of mild steel was polished, prepared, and weighted, $\mathrm{W}_{1}$ (Fig. 2). 
- Immerse the sample in sodium dichromate solutions $(0.1 \mathrm{M} \& 0.5 \mathrm{M})$ for a period of time ( $1-3$ days). Figure 3 shows the protection layer of chrome oxide.

- After 1 day remove the sample from solutions and record the total weight, $\mathrm{W}_{2}$.

- Calculate the weight of coating layer $\left(\mathrm{W}_{2}-\mathrm{W}_{1}\right)$.

- Immerse the coated sample in the corrosive environment (sea water) for 24 hours.

- Remove the sample from sea water and record the total weight, $\mathrm{W}_{3}$.

- Calculate the weight loss $\left(\mathrm{W}_{2}-\mathrm{W}_{3}\right)$.

- Repeat the above steps for the other period of time, environment and time of coating with recording the results for each case.

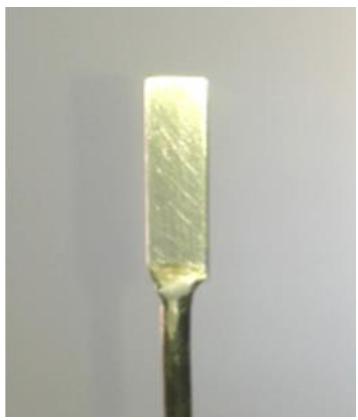

Figure 2: Prepared sample of mild steel.

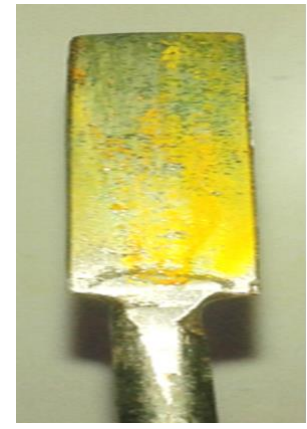

Figure 3: Coated sample of mild steel

To make sure that the coating substance gives the aim that used to, the mild steel has been exposed to the same corrosive environment without applying the coating substance on the surface to produce the protection layer, Figure (4) shows the affected uncoated sample of mild steel before and after the sample exposed and immersed in sea water for 5 days . Figure (5) shows a coated sample of mild steel also before and after immersed in sea water for 5 days. The results obtained for different conditions are illustrated in tables $1-3$ :

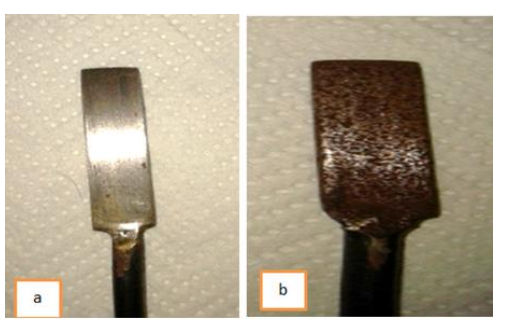

Figure (4): Uncoated sample of mild steel immersed in sea water for 5 days

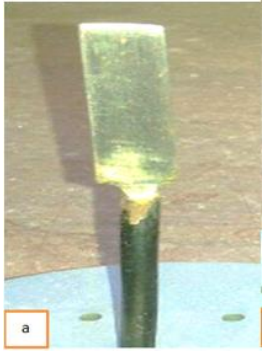

Figure (5): Coated sample of mild steel immersed in sea water for 5 days 
Evaluation of Corrosion Resistance of Mild Steel and Aluminium Using Anodic Inhibitor Method and Passivity

Table (1): Corrosion of mild steel without protection

\begin{tabular}{|c|c|c|c|}
\hline Samples & $\begin{array}{c}\text { Weight of sample, } \\
\mathrm{gm}\end{array}$ & $\begin{array}{c}\text { Time of exposure in } \\
\text { sea water, } \mathrm{hrs}\end{array}$ & $\begin{array}{c}\text { Weight loss } \\
\mathrm{gm} / \mathrm{cm}^{2}\end{array}$ \\
\hline 1 & 26.7253 & 24 & 0.00295 \\
\hline 2 & 27.1127 & 48 & 0.03333 \\
\hline 3 & 26.7285 & 72 & 0.03809 \\
\hline 4 & 26.8365 & 96 & 0.04095 \\
\hline
\end{tabular}

Table (2): Protection of mild steel by $0.1 \mathrm{M}$ sodium dichromate in sea water and air

\begin{tabular}{|c|c|c|c|c|}
\hline Environment & $\begin{array}{c}\text { Sample weight, } \\
\text { gm }\end{array}$ & Coating layer, gm & Weight loss & Exposure time \\
\hline Sea water & 26.5045 & 0.0006 & 0.0005 & $24 \mathrm{hrs}$ \\
\hline Atmosphere & 26.3992 & 0.0007 & 0.00045 & 7 days \\
\hline
\end{tabular}

Table (2): Protection of mild steel by $0.5 \mathrm{M}$ sodium dichromate in sea water and air

\begin{tabular}{|c|c|c|c|c|}
\hline Environment & $\begin{array}{c}\text { Sample weight, } \\
\text { gm }\end{array}$ & Coating layer, gm & Weight loss & Exposure time \\
\hline Sea water & 26.0047 & 0.0031 & 0.0010 & 24 hrs \\
\hline Atmosphere & 25.8415 & 0.0016 & 0.0004 & 5 days \\
\hline
\end{tabular}

\subsection{Aluminium protection (Passivation)}

The Aluminum metal has been considered one of the metals that have the ability to form an oxide layer on the surface comes from the reaction between the environment and the metal surface and this layer works to protect the metal from corrosion [6]. Therefore, to evaluate this property for the Aluminum metal, an aluminum samples were immersed in acids solutions $\left(10 \% \mathrm{v} / \mathrm{v} \mathrm{HCL}\right.$ and $\left.10 \% \mathrm{v} / \mathrm{v} \mathrm{HNO}_{3}\right)$. An oxide layer was formed from the reaction between the Aluminum and Nitric acid where this reaction occurs due to the availability of oxygen atoms in nitric acid. On the other hand, in case of HCL acid this oxide layer could not be formed due to the lake of oxygen in the reaction environment and a reaction of consuming the aluminum was occurred producing aluminum chloride and hydrogen gas (Eq. 2) and this later comes from consuming the electrons resulted from the aluminum to convert the hydrogen ion to hydrogen gas on the aluminum metal surface (Eq. 3). This was clear from monitoring the concentration of hydrogen ion in the reaction solution and the change in $\mathrm{PH}$ value. The results of this monitoring was recorded and presented in table 4. Figure (6) shows the different between two samples of Aluminum where the corroded one immersed in HCL and the protected one immersed in Nitric acid.

$$
\begin{aligned}
& \mathrm{AL}+\mathrm{HCL} \longrightarrow \mathrm{AlCl}_{3}+\mathrm{H}_{2} \\
& 2 \mathrm{H}^{+}+2 \mathrm{e}^{-} \longrightarrow \mathrm{H}_{2}
\end{aligned}
$$




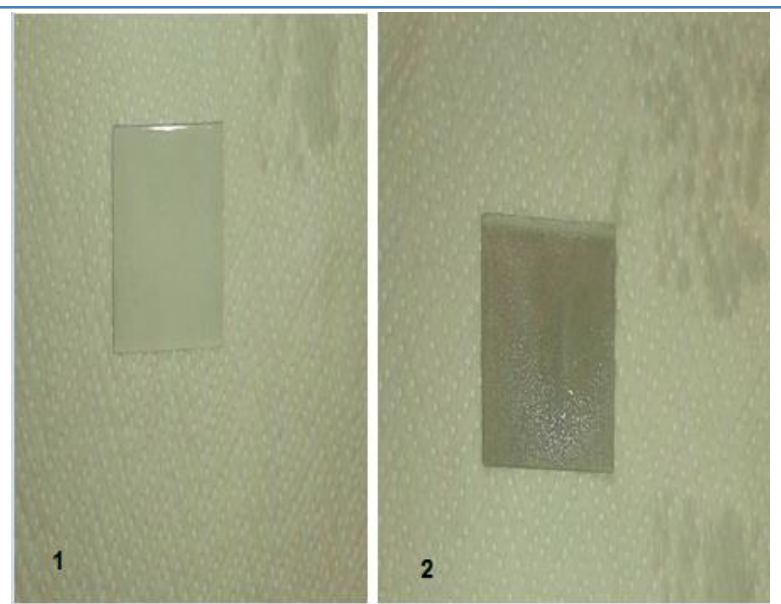

Figure 6: Aluminum sample (1) protected (HNO3) Aluminum sample (2) corroded (HCL)

Table 4: Concentration monitoring of hydrogen ion and $\mathrm{pH}$ at $20^{\circ} \mathrm{C}$

\begin{tabular}{|c|c|c|c|c|}
\hline \multirow{2}{*}{ Days } & \multicolumn{2}{|c|}{$H C L, 10 \% \mathrm{~V} / \mathrm{V}$} & \multicolumn{2}{c|}{$\mathrm{HNO}_{3}, 10 \% \mathrm{~V} / \mathrm{V}$} \\
\cline { 2 - 5 } & $H^{+}$Conc. $\mathrm{mV}$ & $p H$ & $\begin{array}{c}H+\text { Conc. } \\
m \mathrm{~V}\end{array}$ & $p H$ \\
\hline 1 & 271 & 2.89 & 324 & 1.70 \\
\hline 2 & 245 & 4.01 & 321 & 2.24 \\
\hline 3 & 175 & 4.40 & 285 & 2.14 \\
\hline 4 & 156 & 5.40 & 294 & 2.13 \\
\hline 5 & 130 & 5.51 & 263 & 2.59 \\
\hline 6 & 106 & 5.80 & 266 & 2.57 \\
\hline 7 & 101 & 6.90 & 255 & 2.62 \\
\hline \multicolumn{4}{|c|}{ Weight loss in HCL acid solution $=0.9116$ gm after 7 days } \\
\multicolumn{4}{|c|}{ Weight loss in Nitric acid solution $=0.1361$ gm after 7 days } \\
\hline
\end{tabular}

In the table it was clear that the $\mathrm{pH}$ change with time due to the change in concentration of hydrogen ion in hydrochloric acid solution which comes from the passive layer of protection not formed. On the other hand, there was a slight change in the concentration of hydrogen ion in nitric acid because of the formation of protection passive layer. Figure 7 and Figure 8 prove that decreasing the concentration of hydrogen ion leads to increase the $\mathrm{pH}$ of HCL acid solution. In addition, there was a slight decrease in the concentration of hydrogen ion in nitric acid led to also a slight increase in $\mathrm{pH}$ because of the protection layer. 
Evaluation of Corrosion Resistance of Mild Steel and Aluminium Using Anodic Inhibitor Method and Passivity

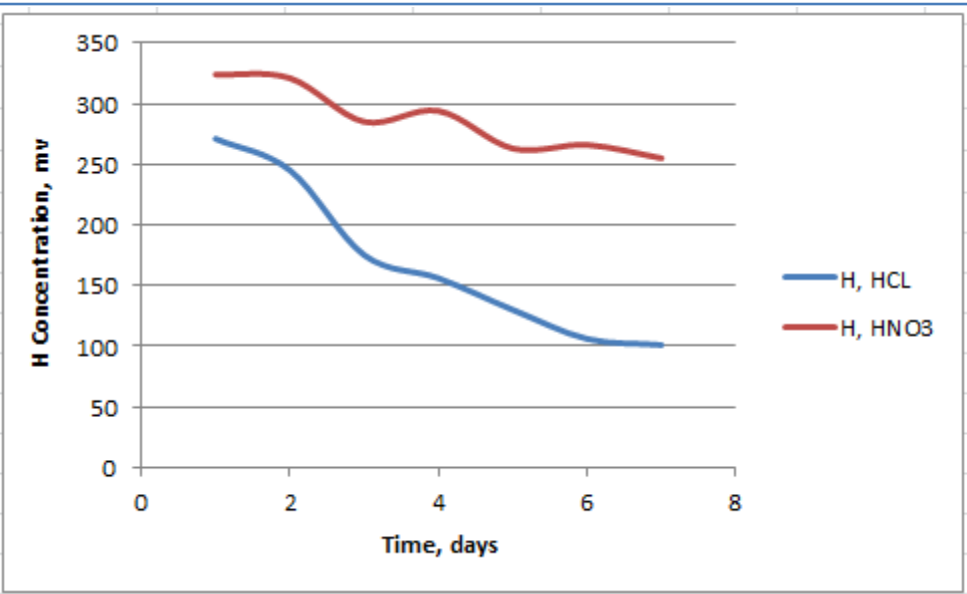

Figure 7: Monitoring of hydrogen ion concentration in HCL \& HNO3 solutions

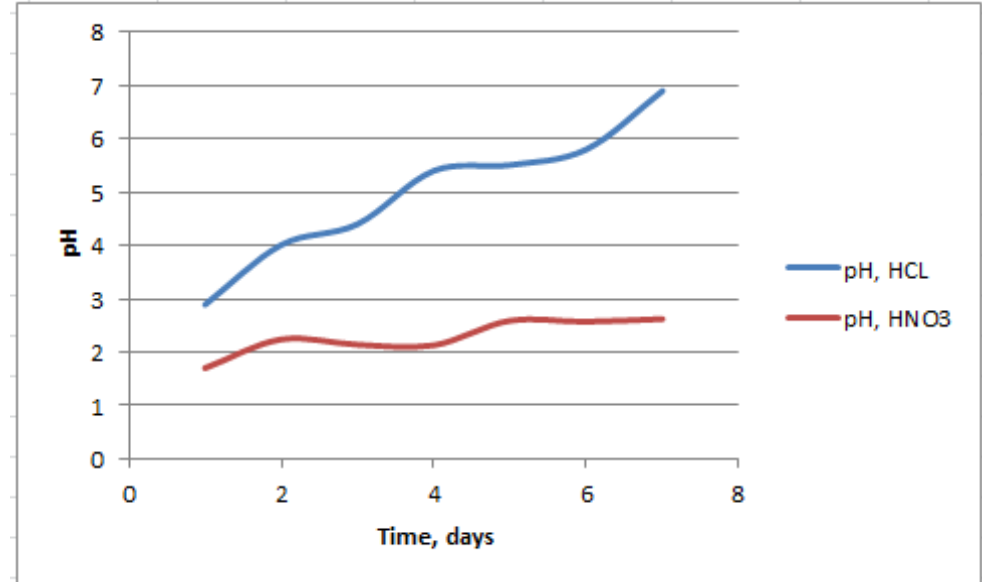

Figure 8: Monitoring of PH in $\mathrm{HCL} \& \mathrm{HNO}_{3}$ solutions

\section{Conclusions}

The results obtained confirmed that the chemical solution of sodium dichromate can be successfully used as chemical inhibitor to protect the mild steel in sea water and atmosphere. Moreover, the most important result achieved in this work that the passive film (protection layer) cannot be formed for all metals and corrosive environments because of the dependency on the reaction between the metal surface and environment.

\section{Acknowledgment}

The authors are thankful to the Chemical \& petroleum Engineering Department, Engineering Faculty, El-Mergib University, Khums Libya, for providing laboratory facilities to complete the research.

\section{References}

[1] P. R. Roberge, “ Handbook of Corrosion Engineering”, New York: Mc Graw Hill Hand-Book, 1999 
Elkais et al., CEST-2018, AIJR Proceedings 2, pp.323-329, 2018

[2] Edrah S., Elkais A., Zambri M. (2016) Anticorrosion of Mild Steel in Sea Water at different temperatures by using green inhibitors "Posidonia oceanica" "1st International Conference on Chemical, Petroleum, and Gas Engineering" at Al-Mergib Unversity, Faculty of Engineering, department of Chemical and petroleum engineering 20 -22 / 2016.

[3] Taleb H. Ibrahim and Mohamed Abou Zour" Corrosion Inhibition of Mild Steel using Fig Leaves Extract in Hydrochloric Acid Solution” Int. J. Electrochem. Sci, 6 (2011) $6442-6455$.

[4] Camila G. Dariva and Alexandre F. "Corrosion Inhibitors - Principles, Mechanisms and Applications", Journal of INTECH (Open Science / Open minds), 2014, Access online on 01/04/2018 at http://dx.doi.org/10.5772/57255.

[5] B. E. Roethell, and G. L. Cox, "Prevention of Corrosion of Metals by Sodium Dichromate as Affected by Salt Concentrations and Temperature” Industrial \& Engineering Chemistry”, 1931, 23 (10), pp 1084-1090

[6] Firas F. Sayyid, Ali M. Ali, and Wadhah A. Tawfek, "Evaluation of Corrosion Resistance of Medium Carbon Steel using different Protection Methods" Journal of Engineering and Technology, 2012, Vol 30, Issue 7 